\title{
A EDUCAÇÃO INTEGRAL NO CONTEXTO DO ENSINO MÉDIO
}

\section{ARTIGO ORIGINAL}

COSTA, Tânia Gomes Ferreira da ${ }^{1}$

COSTA, Tânia Gomes Ferreira da. A Educação Integral no contexto do Ensino Médio. Revista Científica Multidisciplinar Núcleo do Conhecimento. Ano 05, Ed. 05, Vol. 07, pp. 137-146. Maio de 2020. ISSN: 2448-0959, Link de acesso: https://www.nucleodoconhecimento.com.br/educacao/contexto-do-ensino

\section{RESUMO}

O presente trabalho tem como objetivo refletir sobre como a Educação Integral tem sido implementada no contexto do Ensino Médio Brasileiro. Tem-se como problema de pesquisa a discussão acerca dos principais desafios encontrados para fornecer um ensino, de fato, integral, sem que haja o esgotamento do aluno. Parte-se de hipótese de que não adianta apenas enfocar nas horas em que esse aluno irá permanecer nessa escola. É preciso que todas as capacidades cognitivas sejam trabalhadas para que haja uma formação integral do alunado. Esse é o grande desafio: fazer com que as horas a mais na escola acarretem a formação integral a partir de atividades pedagógicas eficientes. A Educação Integral é uma proposta do governo federal que traz, em seu arcabouço, a possibilidade de oferecer uma educação de qualidade que contemple o educando em sua integralidade. Trata-se de ampliar o tempo e espaço do educando no ambiente escolar e agregar a esse contexto diversos componentes

\footnotetext{
${ }^{1}$ Mestranda Em Educação- Universidad Grendal Estados Unidos da América Estado da Florida. Especialização em Gestão de Políticas Públicas em Gênero e RaçaUniversidade Federal da Bahia- UFBA. Especialização em Supervisão, Coordenação, Direção e Pedagogo Escolar- Faculdade São Mateus. Especialização em Orientação Educacional - Faculdades Integradas de Jacarepaguá - FIJ. Graduação em História - Faculdade de Ciências da Bahia - FACIBA. Graduação em Pedagogia Universidade do Estado da Bahia- UNEB.
} 
curriculares que possam complementar o conhecimento já adquirido em sala de aula. Todavia, para que os resultados possam ser efetivamente alcançados, é importante que alguns passos sejam dados, como, por exemplo, a reestruturação das escolas e a qualificação docente para lidar com a inclusão destes saberes. Não é uma tarefa fácil, pois requer recursos financeiros para organizar e adequar o espaço para todas as possibilidades educativas, bem como carece do empenho e envolvimento de toda a equipe da escola, principalmente dos docentes, no sentido de apreender o significado da educação integral e colocar em prática as possibilidades de ensino e aprendizagem.

Palavras-chave: Educação Integral, Ensino Médio, formação integral, desafios.

\section{INTRODUÇÃO}

O presente trabalho tem como objetivo apresentar as perspectivas levantadas pela literatura sobre a inclusão da Educação Integral no ensino médio brasileiro. É notória a interpretação da literatura referente aos benefícios que podem alcançados mediante a inclusão da Educação Integral. Todavia, é compreensível que a caminhada para esse processo ainda se encontra no início e diversos desafios devem ser suplantados a fim de se alcançar os resultados que podem ser almejados com esse formato de educação. Com a aprovação da reforma do Ensino Médio a educação em tempo integral tem sido uma realidade cada vez mais frequente, porém constata-se que são inúmeros os desafios no que toca a adaptação à essa nova realidade. Tem-se, dessa forma, como problema de pesquisa, os desafios e dificuldades para se fornecer uma educação integral.

A justificativa do estudo se dá em razão do fato de que com a nova reforma, é esperado que todas as escolas brasileiras passem a oferecer ensino em tempo integral (BARBOSA; COLARES, 2019). Contudo, parte-se da hipótese de que apenas prolongar as horas desse alunado na escola não acarretará o desenvolvimento integral salientado pela BNCC (Base Nacional Comum Curricular). Considerando esse contexto que é marcado por inúmeros desafios, esta proposta propõe uma revisão da literatura acerca de como tem sido implementada a educação em tempo integral a fim 
de averiguar se a extensão da jornada escolar tem fomentado um ensino, de fato integral. Pensar em tais questões justifica a relevância da pesquisa, uma vez que fatores diversos, como, por exemplo, a falta de infraestrutura, recursos e de qualificação docente dificulta essa implementação em todo o país.

\section{A EDUCAÇÃO EM TEMPO INTEGRAL: IMPLEMENTAÇÃO NO TERRITÓRIO BRASILEIRO}

Uma das principais mudanças ocorridas nas duas últimas décadas concernente ao sistema educacional brasileiro, sobretudo no âmbito do Ensino Médio, foi a inclusão da Educação integral como modelo de oferta de educação básica com aumento do tempo escolar e possibilidade de inclusão de diversos conteúdos, não só teóricos como, também ${ }_{2}$ práticos, capazes de contribuir para o desenvolvimento escolar do aluno. Segundo Branco (2012, p. 112): "os ideais da educação integral não são novos entre os educadores brasileiros. Eles aparecem na história da educação, desde a década de 1930, quando, na ocasião, são colocadas em discussão mudanças necessárias para a reconstrução da educação", bem como "a organização de um sistema escolar único, laico, público e obrigatório para todo" (idem). Conforme o autor, a ideia de Educação Integral perpassa por mais de meio século no Brasil.

Desde o início do século $X X$, os primeiros passos neste sentido começaram a ser traçados, sobretudo pelo Educador Anísio Teixeira, um expoente que marcou época no quesito educacional e que trouxe importantes contribuições, na época, que fomentaram discussões e que, meio século depois, já no início do século XXI, culminou a Educação Integral legalmente instituída, conforme se observa na atualidade (BRANCO, 2012). Apenas no ano de 2007 é que a ideia de escola em tempo integral se torna, de fato, lei no país. Com o advento da Portaria Interministerial № 17 e, posteriormente, com o Decreto Presidencial 7.083, de 2010, estabeleceu-se "que o governo federal assume uma política indutora focando fortemente a implantação da Educação Integral nas escolas públicas brasileiras, tendo como principal objetivo garantir a aprendizagem de todos os alunos" (BRANCO, 2012, p. 114). 
A Educação em Tempo Integral é uma alternativa de reformulação curricular do ensino nas escolas brasileiras que já vem sendo, atualmente, inserida em algumas escolas públicas do país. Configura-se em um aumento do tempo em que o educando passa no ambiente escolar, "propiciando-Ihes maiores oportunidades de inclusão à cidadania e melhorias no currículo escolar" (SANTIAGO; SANTIAGO, 2016, p. 38). Guará (2006 apud BAHIA, 2014, p. 14) traz a seguinte compreensão sobre o que significa Educação Integral:

A concepção da educação integral que a associa a formação integral traz o sujeito como centro das indagações e preocupações da educação. Agrega-se à ideia filosófica de homem integral, realçando a necessidade de desenvolvimento integrado de suas faculdades cognitivas, afetivas, corporais e espirituais, regatando, como tarefa prioritária da educação, a formação do homem, compreendido em sua totalidade (GUARÁ, 2006 apud BAHIA, 2014, p. 14).

A proposta da Educação Integral traz, em seu arcabouço, a intenção de inserir no processo do ensino e aprendizagem do educando outros contextos que não os vivenciados rigidamente em sala de aula. A ideia de propor a Educação Integral nas escolas brasileiras perpassa pela compreensão da necessidade de se oferecer serviços que compreendam as necessidades do aluno de uma forma integral, ou seja, pressupõe-se políticas integradas que considerem, além da educação, outras demandas dos sujeitos, "articuladas entre os campos da educação, do desenvolvimento social, da saúde, do esporte, da inclusão digital e da cultura" (BRASIL, 2009, p. 31). A Educação integral, como o próprio nome já define, é a oferta de oportunidades para o desenvolvimento do processo de ensino e aprendizagem de forma a permitir que a educando seja formado, não só do ponto de vista científico, mas também em diversas outras condições (BAHIA, 2014).

Não se pode pensar na inserção da Educação Integral sem considerar os aspectos inerentes ao tempo e espaço. $O$ tempo será aumentado com a permanência prolongada do educando na escola. Com isso, as oportunidades de inclusão de diversas práticas do saber se tornam possíveis. É importante aproveitar cada minuto 
deste educando no seu ambiente escolar. Nessa perspectiva, o espaço, também, deve ser otimizado, aproveitando-se tudo o que a escola pode oferecer, além da sala de aula. A ideia de Educação Integral não pode ser concebida sem que se inclua, também, os espaços extramuros, que são excelentes condicionantes para troca de saberes e experiências sociais e culturais por parte dos educandos (BRANCO, 2012). A proposta de Educação Integral possibilita criar espaços de aprendizagem fora das salas de aula. Educação não deve ser pensada como algo preso às paredes de uma sala de aula, muito menos como algo engessado em regras impostas.

Tais espaços mais viáveis com a Educação Integral são essenciais e necessários ao desenvolvimento social e cultural do indivíduo (PEREIRA; VALLE, 2017). Abordar a Educação Integral a partir da ampliação de espaços, tempos e oportunidades educativas na escola e fora dela: "implica um compromisso com a educação pública, gratuita e sistêmica para que cumpra com sua função social, transmitindo às novas gerações os conhecimentos historicamente acumulados" (BAHIA, 2014, p. 15). Na compreensão da Educação Integral, é importante destacar que uma das propostas visíveis neste formato de ensino é a busca por oferecer condições que atendam ao aluno na sua integralidade. Nessa perspectiva, oportuniza-se, ao aluno, o que a literatura denomina tempo qualificado, ou seja, aproveita-se o tempo disponível para incrementar tudo o que for necessário para o processo de ensino e aprendizagem do aluno (SÔNEGO; GAMA, 2018).

A proposta da Educação Integral, ao vislumbrar a ideia de tempo qualificado, oferece, ao aluno, uma mescla de atividades educativas diferenciadas que, ao fazê-lo, "contribui para a formação integral do aluno, para a superação da fragmentação e do estreitamento curricular e da lógica educativa demarcada por espaços físicos e tempos delimitados rigidamente" (BRASIL, 2009, p. 30). A educação, nesse contexto, não deve ser parcial ou fragmentada, devendo ser concebida de forma a complementar todas as necessidades de desenvolvimento social e cultural do indivíduo. Assim, "a integração da cultura, da saúde, do transporte, da assistência social, dentre outros, com a educação possibilita a integralidade da educação" (RIBEIRO, 2017, p. 80). Zanardi (2016, p. 84) destaca que a ampliação do tempo de 
ensino com a inserção da Educação Integral visa "proporcionar um avanço significativo para diminuir as desigualdades sociais e ampliar democraticamente as oportunidades de aprendizagem".

Zanardi (2016, p. 84) observa que os resultados não são alcançados apenas com o aumento do tempo do aluno na escola. É preciso que a escola se reoriente para oferecer ao aluno as condições necessárias para assisti-lo em sua integralidade. Assim, a questão a ser enfrentada, segundo a autora, "é que a escola em Tempo Integral deve ser mais que a permanência prolongada do aluno na escola, ou seja, a oferta deve ser mais que o depósito de crianças alternando aulas e atividades extracurriculares". Para Pereira e Valle (2017, p. 1), a estruturação e reestruturação de propostas tanto didáticas quanto metodológicas educacionais no turno oposto, complementando o ensino no turno regular, propõe um leque de ações alinhados na pretensão de orientar todos os atores (estudantes, educadores, pais, comunidade) "acerca do valor social da educação, através da conscientização destes em relação à importância da formação do educando".

\section{DESAFIOS QUE PERPASSAM A EDUCAÇÃO INTEGRAL}

Pensar numa Educação Integral capaz de atender plenamente os anseios dos alunos não é tarefa fácil. Rever e reafirmar o currículo perpassa por muitas mudanças, inclusive de concepção por parte dos educadores. Promover um novo currículo que englobe tudo o que diz respeito a integralidade do indivíduo que estuda não é tarefa das mais fáceis. Para Ribeiro (2017, p. 83), é um grande desafio organizar um currículo e todo o trabalho pedagógico escolar "na perspectiva de atender aos ideais de uma educação integral em tempo integral, haja vista as diversas exigências que se impõem contemporaneamente a essa perspectiva de currículo". Assim sendo, esse é um dos fatores que inviabilizam a implementação efetiva e eficiente da educação em tempo integral, e, ainda, integral.

O currículo deve ser organizado mediante a inclusão de diversos componentes que são fundamentais para que a atenção a educação do indivíduo seja integral. Assim sendo, saberes relacionados à sua vida social e cultural devem ser levados em 
consideração. Além disso, o espaço e o tempo a mais que o educando passará na escola deverá ser compreendido como um momento único capaz de proporcionar aos alunos a possibilidade de se desenvolver não só enquanto educando, mas sim, enquanto cidadão. Galian e Sampaio (2012 apud RIBEIRO, 2017, p. 83) reforçam que o desafio da educação integral não é tarefa das mais fáceis, necessitando uma reorganização curricular e estrutural do sistema de ensino brasileiro:

Se ampliar o tempo de permanência das crianças está atrelado ao objetivo de buscar a aprendizagem de todos, os meios para fazê-lo deverão passar pela reconfiguração de tempos, espaços e, também, de saberes. A relação da escola com a cultura local e com as outras instâncias educativas da região exigirá, de certo, como algumas propostas já atestam, uma nova composição e articulação do currículo e uma nova organização de tempos, espaços e trabalho da escola. Não poderia se tratar, portanto, de simplesmente manter a escola como sempre foi e preencher os novos períodos com atividades quaisquer, não diretamente ligadas a este fim.

A literatura revisada aponta que, embora a Educação Integral seja, atualmente, uma realidade, na prática ainda há um longo caminho a percorrer, para que, de fato, ela possa produzir os resultados esperados. Para Zanardi (2016, p. 86), a educação integral deve ser capaz de responder:

A uma multiplicidade de exigências, ao mesmo tempo em que deve objetivar a construção de relações na direção do aperfeiçoamento humano, o que comporta na oferta de possibilidades para que o indivíduo possa evoluir, plenamente, em todas as suas dimensões (cognitiva, corpórea, social, cultural, psicológica, afetiva, econômica, ética, estética, entre outras).

De acordo com o autor, esta multiplicidade de exigências só tem condições de emergir mediante uma ação dialógica, com articulação de todos os atores envolvidos no processo de ensino aprendizagem. É a partir desta articulação que os sujeitos se 
viabilizam e a orientação consegue se fundamentar na concepção ideal de Educação Integral. No tocante aos desafios para o futuro da Educação Integral no Brasil, Santiago e Santiago (2016) ressaltam a necessidade de readequação não só do currículo, mas também da estrutura das instituições escolares, além da qualificação dos docentes para que possam ofertar, nas horas a mais dos educandos na escola, conteúdos que os mesmos possam inserir no seu processo de desenvolvimento escolar.

De acordo com os autores, a capacitação docente, bem como a reorganização da estrutura escolar são os pilares para que as ações de uma educação em tempo integral viabilizem-se na sociedade de forma positiva e concisa. Na medida em que tanto a equipe de professores busca se adaptar à nova realidade e a estrutura escolar se reorganiza para tal fim, torna-se possível almejar resultados positivos no projeto escolar. Para Santiago e Santiago (2016), ainda há uma distância a ser percorrida para que a Educação Integral seja plenamente efetiva no país. Contudo, por outro lado, as escolas precisam adequar espaços físicos, bem como qualificar educadores e promover todo um reordenamento curricular dentro dos muros escolares a fim de que a ideia saia do papel e se consolide na prática.

A literatura aponta que dentre as experiências oficiais tangentes à implementação da educação em tempo integral, destaca-se a abrangência de estudantes atendidos por essa modalidade (SANTOS; SILVA, 2019; BARBOSA; COLARES, 2019; EVANGELISTA; MELO; CARVALHO, 2019; TAVARES, 2017). Dentre os objetivos da ampliação da jornada escolar, está o desenvolvimento das potencialidades discentes, oferecendo, para isso, condições para que construam diferentes saberes a partir do contato com disciplinas além das tradicionais que compõem o currículo escolar, porém, como ressaltamos, a falta da qualificação docente, recursos insuficientes e uma má infraestrutura dificultam tal implementação em todo o país, o que dificulta o diálogo entre saberes escolares e comunitários a serem incorporados com a ampliação da permanência na escola.

O "ideal" seria a proposição de oficinas e/ou atividades diversificadas que possam contribuir para com a formação integral, mas os fatores citados impedem esse 
oferecimento (SOTERO; CUNHA; GARCIA, 2019; SANTOS; PEREIRA; MELLO, 2019; FERREIRA, 2019; MARTINS; MENEZES, 2019). Dentre essas dificuldades, em uma perspectiva nacional, a infraestrutura de nossas escolas é o principal empecilho para que haja um ensino, de fato, integral. Por outro lado, o contato com organizações sociais e coletivas também não ocorre na prática, o que inviabiliza a construção de saberes comunitários, um dos objetivos da nova reforma do Ensino Médio com a ampliação da jornada. Há, também, o enfoque em uma educação que é compreendida, unicamente, como responsável por repassar informações (FERREIRA, 2019). É urgente, então, a mudança de postura.

É crucial que se enfatize uma educação para além da lógica escolar, e, para isso, é preciso romper com concepções relacionadas à institucionalização total das crianças e adolescentes, pois, dessa forma, esses sujeitos são exilados de um convívio social mais amplo, pois ficam restritos às dependências da escola durante todo o dia (SANTOS; SILVA, 2019; BARBOSA; COLARES, 2019; EVANGELISTA; MELO; CARVALHO, 2019; TAVARES, 2017; FERREIRA, 2019). Aderir a uma concepção de educação e aplicá-la ao contexto real do ensino é um dos principais desafios. É importante, ainda, o investimento público de longa duração para que a proposta de educação e formação integral possa se consolidar na prática. Há, ainda, outras medidas que inviabilizam esse ensino, como, por exemplo, os debates decenais em torno da educação que envolvem todos os entes federativos.

De acordo com Fernandes (2019), tais debates são marcados pela tentativa de negar a diversidade humana, e, ainda, o caráter sociopolítico e cultural da educação. Para ele, a nova reforma do Ensino Médio possui um viés meramente tecnicista, e, dessa forma, nega os princípios basilares da educação básica preconizados, em 1996, pela Lei de Diretrizes e Bases da Educação Nacional (Lei 9.394/96). Aponta, ainda, que a BNCC está alinhada a uma lógica desenvolvimentista e pragmática, colaborando com movimentos como o Escola sem Partido (ESP). Reitera, também, que não foi apenas o Programa Mais Educação que sofreu retrocessos nos últimos anos, mas sim todas as iniciativas políticas que visam atender as demandas sociais no âmbito da 
educação. Frisa que o momento atual faz com que seja necessária a construção de uma lógica capaz de retomar as políticas públicas que privilegiam a educação.

Essa educação precisa ser integral e popular (SOTERO; CUNHA; GARCIA, 2019; SANTOS; PEREIRA; MELLO, 2019; FERREIRA, 2019; MARTINS; MENEZES, 2019). Nesse contexto, uma educação, de fato, integral, pressupõe que pensemos em currículos outros, isto é, em novas epistemologias. Para tanto, é crucial que se rompa para com paradigmas positivistas e pragmáticos que alicerçam a instituição escolar (FERREIRA, 2019). Como enfatizado, a escola oferece um currículo marcado pela fragmentação e dicotomização entre corpo e mente, lazer e trabalho, disciplina e indisciplina. Para Ferreira (2019), os sujeitos não podem ser compreendidos em sua integridade quando se adere a fragmentação e dicotomização. Deve-se reconhecer a criança e o adolescente em sua integralidade e integridade. Esta é uma condição para que se adira um novo olhar pedagógico acerca do ensino-aprendizagem.

Assim sendo, é necessário que a prática docente opere para além de ações já sistematizadas ao longo da história escolar. Há que se considerar, então, aspectos como a formação cidadã, o direito ao lazer, ao lúdico e ao afeto no contexto da educação (FERREIRA, 2019; SANTOS; SILVA, 2019; BARBOSA; COLARES, 2019; EVANGELISTA; MELO; CARVALHO, 2019; TAVARES, 2017). Nesse contexto, se a oferta da educação integral não acompanhar a implementação de políticas públicas direcionadas e que rompam para com as desigualdades sociais, pode-se ter um efeito negativo com a ampliação dessa jornada e aprofundar as desigualdades já existentes. A instituição escolar, por outro lado, não deve ser responsabilizada por todo o rompimento, pois muitos os sujeitos e instituições que podem contribuir para com a adesão a um novo fazer pedagógico.

\section{CONSIDERAÇÕES FINAIS}

O estudo aqui proposto apresentou a realidade atual concernente à Educação Integral no Brasil, atualmente já implícito em algumas escolas brasileiras. Ao se observar o que a literatura aborda sobre o objeto deste estudo pôde-se compreender que a Educação Integral é uma proposta do governo federal que traz, em seu arcabouço, a 
possibilidade de oferecer uma educação de qualidade que contemple o educando em sua integralidade. Trata-se de ampliar o tempo e espaço do educando no ambiente escolar e agregar, a esse contexto, diversos componentes curriculares que possam complementar o conhecimento já adquirido em sala de aula.

Todavia, para que os resultados possam ser efetivamente alcançados, é importante que alguns passos sejam dados, como, por exemplo, a reestruturação das escolas e a qualificação docente para lidar com a inclusão destes saberes. Os principais desafios abordados pela literatura são justamente os citados ao longo da discussão. Não é tarefa fácil, pois requer recursos financeiros para organizar e adequar o espaço para todas as possibilidades educativas, bem como carece do empenho e envolvimento de toda a equipe da escola, principalmente dos docentes, no sentido de apreender o significado da educação integral e colocar em prática as possibilidades de ensino e aprendizagem.

\section{REFERÊNCIAS}

BAHIA. Superintendência da Educação Básica. Coordenação de Educação Integral. Programa de Educação Integral (PROEI): da ampliação do tempo e do currículo escolar à formação humana integral. Salvador: Governo do Estado da Bahia, 2014.

BARBOSA, L. L.; COLARES, M. L. I. S. Reforma do Ensino Médio: desafios e possibilidades da educação integral. Cadernos de Pesquisa, v. 26, n. 2, p. 295-316, 2019.

BRANCO, V. Desafios para a implantação da Educação Integral: análise das experiências desenvolvidas na região sul do Brasil. Educar em Revista, Curitiba, v. 1, n. 45, p. 111-123, jul.-set. 2012.

BRASIL. Ministério da Educação. Secretaria de Educação Continuada. Educação Integral: texto referência para o debate nacional. Brasília: MEC, 2009.

eVAngelista, A. P.; MELO, L. de. F.; CARVAlho, M. C. A. de. A política de Educação em Tempo Integral no Ensino Médio do estado do Acre: bases político- 
ideológicas que orientam o programa. Revista Docência e Cibercultura, v. 3, n. 2, p. 271-286, 2019.

FERREIRA, J. H. Tempo e Educação Integral. @ rquivo Brasileiro de Educação, v. 7, n. 16, p. 219-239, 2019.

MARTINS, M. da. S.; MENEZES, N. C. R. Pensamento complexo e Educação Integral. In: Salão de Ensino e de Extensão, 2019.

PEREIRA, M. P. T.; VALLE, F. F. do. Educação Integral e Integrada - novos tempos, espaços e oportunidades educativas. Debate Educação, v. 33, n. 7, 2017.

RIBEIRO, Madison Rocha. A relação entre Currículo e Educação Integral em tempo integral: um estudo a partir da configuração curricular do Programa mais educação. 2017. 240 f. Tese (Doutorado em Ciências da Educação) - Universidade Federal do Pará, Belém, 2017.

SANTIAGO, L. A.; SANTIAGO, T. A. Educação: tempo integral. Revista Científica FAESA, v. 12, n. 1, p. 38-42, 2016.

SANTOS, M. L. S. dos.; SILVA, K. N. P. Avaliações em larga escala e educação integral no ensino médio. Revista e-Curriculum, v. 17, n. 3, p. 1312-1331, 2019.

SANTOS, C. C. de. F.; PEREIRA, R. da. S.; MELLO, M. B. de. Educação Gerencial nas políticas públicas de Educação em Tempo Integral do governo Lula/Dilma ao governo Temer. Estudos IAT, v. 4, n. 2, p. 109-125, 2019.

SÔNEGO, F.; GAMA, M. E. R. A escola na perspectiva da Educação Integral. Rev. Gest. Aval. Educ., v. 7, n. 14, p. 135-145, jan. 2018.

SOTERO, M. da. C.; CUNHA, E. B. J.; GARCIA, V. A. Educação Integral e atendimento educacional especializado: como essas políticas são implementadas ao mesmo tempo? Cadernos CEDES, v. 39, n. 108, p. 237-250, 2019. 
TAVARES, A. M. A formação continuada de professores na escola de tempo integral e a possibilidade da reestruturação curricular para a implantação da educação integral. 2017. 148f. Dissertação (Mestrado em Educação) - Universidade Federal do Pampa, Jaguarão, 2017.

ZANARDI, T. C. A. Educação Integral, tempo integral e Paulo Freire: os desafios da articulação conhecimento-tempo-território. E-Curriculum, v. 14, n. 1, p. 82-87, mar. 2016.

Enviado: Março, 2020.

Aprovado: Maio, 2020. 